\title{
Tuz ve PEG kaynaklı kuraklık stresinin çok yıllık çim (Lolium perenne L.) çeşitlerinde fide gelişimine etkisi
}

\author{
Effects of salt and PEG-induced drought stress on seedling performance of perennial ryegrasses (Lolium \\ perenne L.) cultivars
}

\section{Merve Birhan YILMAZ ${ }^{1 / \infty}$, Şule KISAKÜREK ${ }^{2}$ (D)}

${ }^{1}$ Cukurova University, Faculty of Agriculture, Institute of Science, Adana, Turkey.

${ }^{2}$ Kahramanmaraş Sutcu Imam University, Faculty of Forest, Department of Landscape Architecture, Kahramanmaraş, Turkey.

MAKALE BILGISI / ARTICLE INFO

Makale tarihçesi / Article history:

DOI: $\underline{10.37908 / m k u t b d .735925}$

Geliş tarihi /Received:13.05.2020

Kabul tarihi/Accepted:13.07.2020

\section{Keywords:}

Emergence rate (\%), drought stress, perennial ryegrass, salinity.

\footnotetext{
Corresponding author: M.Birhan Yılmaz

$\triangle:$ merve94yilmaz@gmail.com
}

\section{ÖZET / A B STRACT}

\begin{abstract}
Aims: This study was conducted to determine the response of some perennial ryegrass cultivars to salt and drought stress during seedling growth stages.

Methods and Results: Four perennial ryegrass cultivars (Apple GL, Ecologic, Barminton and Solstic II) were used as the seed material. Five different doses of Polyethylene Glycol $(0,-0.4,-0.8,-1.2$. ve -1.6 MPa) PEG6000 and salt concentration $(0,50,100,150$ ve $200 \mathrm{mM}) \mathrm{NaCl}$ were used to generate drought stress in seedling growth stages of perennial ryegrass. Seedling emergence experiments were carried out in plastic containers filled with a mixture of sand and peat placed into a growth cabinet with 4 replications in factorial arrangement of Completely Randomized Design (CRD). Tolerance of Lolium perenne cultivars seedling development to salinity and drought stress caused by, sodium chloride and PEG were investigated. As a result of the research in salt application, cultivars, salt and cultivars $X$ salt interactions were significant for examined traits except for root length. In PEG application cultivars, PEG and cultivars X PEG interaction were significant for all parameters, except for root length and shoot length. Generally, increased doses of PEG and salt stress caused remarkable decreases in all examined traits.

Conclusions: Perennial cultivars responded differently with regard to examined traits in seedling emergence. It can be concluded that salt and PEG-6000 was useful agent to create drought stress seedling growth of perennial ryegrass, but greater doses and osmotic potentials lower than $(150 \mathrm{mM})$ and $(-1.2 \mathrm{MPa})$ could be applied to better determine the drought stress tolerance of perennial ryegrass cultivars.

Significance and Impact of the Study: In today's world, where the effects of global warming are increasingly felt, it will be very important to identify the drought problem and species and varieties tolerant to the use of alternative water resources. It is also important to identify the species and varieties tolerant to drought and salinity problems in the short term. Testing the cultivars that we will use in grass areas with a 21-day study and determining the appropriate cultivars that is tolerance/ resistant to salinity or drought is important for the sustainability of the grass areas.
\end{abstract}




\section{GíRiş}

Çim alanlar açık yeşil alan sistemlerinin önemli bir parçası olmanın yanı sıra estetik ve ekolojik birçok fonksiyonu bulunmaktadır. Bu fonksiyonlar görsel katkının yanı sıra ortam ıSısını düşürmek, hava kirliliği ve erozyonu önlemek vb sayılabilir. Bu fonksiyonların yerine getirilmesi kuşkusuz sağlıklı bitki gelişimi ile mümkün olabilmektedir. Sağlıklı bitki gelişimi için bitkilerin ekolojik isteklerinin karşılanması önemlidir. Çim bitkilerinin önemli ekolojik istekleri arasında su ihtiyacı bulunmaktadır. Bu ihtiyaç karşılanmadığı durumda beklenen fonksiyonların yerine getirilmesi olanaksızlaşır. Çim bitkilerinin su ihtiyacl, son yıllarda oluşan küresel iklim değişikliği nedeni ile yağıs düzeninin değişmesi su kaynakları üzerinde oluşan baskılar nedeni ile su kısıtlamasını ve alternatif su kaynaklarının(arıtma suyu, deniz suyu, bataklık suyu ve atık sular) kullanımını ve kuraklığa dayanıklı çim türlerinin gündeme getirmektedir. Lolium perenne çim karışımları içerisinde en yüksek( \%20-25) oranda kullanılan bir çim türüdür (Avcıoğlu, 2014). Diğer serin ve sıcak mevsim çimlerle karışım olarak kullanılabildiği gibi saf, ikili ve üçlü karışım olarak da kullanılabilmektedir. (Yılmaz ve Hurmanlı, 2016; Yılmaz ve ark., 2018).

Çim alanlarda alternatif su kaynaklarının kullanılması çim bitkilerinde bir takım tepkiler oluşmasına neden olmaktadır. Çim türlerinde büyümenin azalması, bitkinin solgunluk göstermesi, besin maddesi dengesizlikleri, spesifik iyon toksisitesi ( $\mathrm{Na}$ ve $\mathrm{Cl}$ gibi), uzun vadeli hayatta kalma yeteneğinin azalması gibi tuzluluk stresi tepkilerine neden olmaktadır (Carrow ve Duncan, 1998). Tuzluluk çimlenmede azalmaya veya çimlenmenin gerçekleşmemesine (AşCI, 2011), bitkilerde ise verim kayıplarına ve ölümlere neden olabilmektedir. Çim alanlarda tuzun yarattığı olumsuz etkilerin giderilmesinde tuza dayanıkı türlerin seçimi önemlidir. Kuraklık stresi, bitkinin ihtiyaç duyduğu suyu alamama durumunda ortaya çıkan stres durumudur. Bitki yetiştiriciliğinde çimlenme ya da ilk gelişme dönemlerinde meydana gelen kuraklık, çimlenmeyi olumsuz etkilediğinden birim alanda yeterli bitki sayısına ulaşılmasına engel olmaktadır. Birim alanda yeterli bitki sıklığına ulaşmak için su kısıtı olan alanlarda belli oranda çimlenebilen çeşitlerin seçimi çim alanlarda başarıyı artırmaktadır. Kuraklığa dayanıklılığı tespit etmek için değişik testler kullanılmaktadır. Kuraklık stresine dayanıklı türlerin tespit edilmesinde; kök yoğunluğu ve uzunluğu, kök-gövde dağılımı ve erken büyüme gücü ve çimlenme yüzdesi testleri kullanılan yöntemler olarak kabul edilmektedir. Dhanda ve ark. (2004) Lolium perenne türünün çimlenme oranı bakımından $8 \mathrm{dS} \mathrm{m}^{-1}$ tuzluluk seviyesine kadar toleransa sahip olduğunu, bu seviyeden sonra çimlenme ve gelişmede sorunlar yaşadığını bildirmiştir (Nizam, 2011). Rouhi ve ark. (2011) dört buğdaygil yem bitkisi türüne (Festuca ovina, Festuca arundinacea, Agropyron cristatum ve Bromus inermis) PEG 6000 ile oluşturulan farklı kuraklık stresi $(0,-0.4,-0.8$ ve -1.2 $\mathrm{MPa}$ ) uygulamasının çimlenme özelliklerine etkisi araştırmasında, artan kuraklık şiddetine bağı olarak çimlenme oranı, çimlenme hızı, fide boyu ve fide kuru ağırlığında azalma olduğunu ayrıca, (-1.2 MPa) kuraklık uygulamasında Festuca ovina ve Festuca arundinacea türlerinde çimlenmenin oluşmadığını bildirmişlerdir. Borawska-Jarmułowicz ve ark. (2017) Lolium perenne L. ve çayır salkım otu çeşitlerinin farklı ışıklanma sürelerinde tuzluluk $(0,100$ ve $200 \mathrm{mM})$ ve kuraklık (0, $0.3,-0.6$ ve $-1.2 \mathrm{MPa}$ ) uygulamalarının tuzluluğun artmasıyla çimlenme süresinin uzadığı, sap ve kök uzunluğunun kısaldığı, kök ağırlığı artarken sap ağırlığının azaldığı, kuraklık miktarı arttıkça, çimlenme oranı azalmakta hatta Lolium perenne $\mathrm{L}$. çeşitlerinde birinde ($0.6 \mathrm{MPa}) \mathrm{da}$, salkım otu çeşidinde $(-0.6 \mathrm{MPa})$ ve $(-1.2$ $\mathrm{MPa}$ ) uygulamasında çimlenmenin olmadığı, kuraklığı arttıkça çimlenme süresinin uzadığı, sap ve kök uzunluğu ve ağırlığının azaldığını bildirmişlerdir.

Günümüzde artan çevre sorunları ve küresel ısınma sonucu değişen iklimsel parametreler su kıtlığı ve alternatif su kaynaklarının kullanımını gündeme getirecektir. Dünya üzerinde 2.4 milyon insan yüksek oranda su kıtlığı olan bölgelerde yaşamaktadır (Okı ve Kanae, 2006; Osakabe ve ark., 2014). Kuraklık stresinin olduğu alanlar dünyanın \%26'sını, mineral stresinin olduğu alanlar ise \% 20'sini oluşturmaktadır (Blum, 1986). Su kıtlığı ve alternatif su kaynakları kullanımı kuraklığa ve tuz stresine dayanıklı çeşitlerin belirlenmesi estetik ve işlevsel birçok öneme sahip çim alanların tesisi için ayrıca önem taşımaktadır. Alternatif su kaynaklarının kullanımasının yanı sıra tuzluluk problemi olan alanlarda çim bitkilerinin kullanım olanaklarını artırması açısından da önemlidir. Bu noktadan hareketle, çalışma çim alanların tesisinde en çok ve en yüksek oranda kullanılan bir çim türü olan Lolium perenne türüne ait çeşitlerin farklı kuraklık ve tuz yoğunluklarının fide çıkış oranı ve fide gelişimi üzerine etkisini belirlemek amacı ile gerçekleştirilmiştir.

\section{MATERYAL ve YÖNTEM}

Araştırmanın ana materyalini Lolium perenne L. çim türünün Ecologic, Barminton, Apple GL, Solistice II, çeşitleri oluşturmaktadır. Araştırmanın yardımcı materyallerini ise iklim odası, laboratuvar malzemeleri 
(toprak, torf, saksı, kimyasallar $\mathrm{NaCl}$ ve PEG 2000 solüsyonu vb.) oluşturmaktadır.

Lolium perenne çeşitlerinin kuraklık ve tuz stresine toleranslarını belirlemek amacı ile yürütülen çalışmada, kuraklık ve tuz stresini belirlemek amacı ile iki deneme " Tesadüf Bloklarında Bölünmüş Parseller Deneme Deseni 'ne göre kurulmuş ve 20 gün süreyle devam ettirilmiştir. Denemeler 4 tekerrürlü ve her tekerrürde 50 tohum olacak şekilde kurulmuştur. Her iki denemede yeterli büyüklüğe sahip plastik kaplarda $(97 \times 165 \times 90 \mathrm{~mm})$ torf $(\mathrm{pH}, 5.5-6.0$; NKP 14-10-18 m3de $1 \mathrm{~kg}$; torf kalınlığı 0.5 $\mathrm{mm}$, Klasmann TS1 Almanya) ve steril dere kumu karışımı (1:1) kullanılmış, sterilizasyonu yapılımış çim tohumları 1 $\mathrm{cm}$ derinliğe ekilmiş ve iklim odası ortamında yürütülmüştür. Her iki denemede tohum sterilizasyonu sodyum hipoklorit içerisinde $1 \mathrm{dk}$. tutulması ile gerçekleştirilmiştir. Tuz stresi denemesi için ihtiyaç duyuldukça her saksıya yeteri kadar test solüsyonlarından $(0,50,100,150$ ve $200 \mathrm{mM}) \mathrm{NaCl}$ dozlarında oluşturulan tuz solüsyonu ve saf su uygulanarak bitkiler yetiştirilmiştir. Kuraklık stresi çıkış denemesi: kuraklık stresini belirlemek amacı ile. $(0,-0.4$, $-0.8,-1.2$ ve $-1.6 \mathrm{MPa}$ ) osmotik potansiyelde ki PEG-6000 solüsyonları her saksıya yeterli miktarda uygulanarak bitkiler yetiştirilmiştir. İlim odasında (25 OC \pm 5 OC) sıcaklık ve 70-80 nispi nem yetiştirilen bitkiler 20. gün sonunda sayılarak çıkış yüzdesi (\%) ve ortalama çıkış süresi (gün), fide boyu, kök uzunluğu, fide kök yaş ağırlıkları ile fide ve kök kuru ağırlıkları belirlenmiştir.

Denemeler sonucunda yapılan ölçüm ve hesaplamalar için saksıda tesadüfen seçilip köklü olarak sökülen 10 bitkinin kökleri musluk suyunda dikkatli yıkanacak ve saf su ile iyice temizlenecek ve fide boyu, kök uzunluğu, fide yaş ağırlığı, fide kuru ağırlığı, kök yaş ağırlığı ve kök kuru ağırlığı alınmıştır.

1. Çıkış Oranı (\%): 21. gün sonunda çıkan fideler sayılarak (çıkan fide sayısı/toplam tohum sayısı) x 100 formülü ile çimlenme oranı \% olarak hesaplanacaktır (Akıncı ve Çalışkan, 2010).

2. Çıkış İndeksi: Her gün çıkan fide sayım günlerine bölünmesiyle aşağıdaki formüle göre bulunmuştur (Wang ve ark., 2004).

$\mathrm{Gl}=\Sigma(\mathrm{Gi} / \mathrm{Tt})$

GI: Çimlenme indeksi; Gi: i. günde çimlenen tohum oranı; Tt: Sayım günü

3. Fide Uzunluğu ( $\mathrm{mm}$ ): Deneme sonunda tesadüf olarak seçilen 10 bitkinin fide uzunluğu milimetrik cetvelle ölçülerek belirlenmiştir.
4. Kök Uzunluğu (mm): Fide boyu ölçülen bitkilerde kök uzunluğu milimetrik cetvelle ölçülerek belirlenmiştir.

5. Fide Yaş Ağırlığı (mg): Seçilen bitkilerin yaş ağırlıkları hassas terazide tartılarak saptanmıştır.

6. Kök Ağırlığı (mg): Seçilen bitkilerin kök yaş ağırlıkları hassas terazide tartılarak saptanmıştır.

Araştırmadan elde edilen değerler SAS-JMP istatistik paket programı kullanılarak "Tesadüf Parsellerinde Faktöriyel Deneme Desenine" göre varyans analizine tabi tutulmuştur. $F$ testi yapılarak farklılıkları tespit edilen özelliklerin ortalama değerleri Tukey $(P<0.05)$ çoklu karşılaştırma testine göre gruplandırılmıştır. Değerlendirme stres kaynağı (Tuz ve PEG 6000) bazında ayrı ayrı yapılıp ve yorumlanmıştır.

\section{BULGULAR ve TARTIŞMA}

Deneme sürelerinin bitiminde tüm ölçüm ve hesaplamalar sonucunda çeşit, tuz yoğunluğu ve çeşit $X$ tuz yoğunluğu interaksiyonunun $(p<0.01)$ fide çıkış oranı yönünden önemli olduğu bulunmuştur. Çizelge $1^{\prime}$ de izlendiği gibi çeşitlere bağlı olarak belirlenen ortalama çıkış oranları \% 25.9 ile \% 50.0 arasında değişmiştir. En yüksek çıkış oranı Solstice II çeşidinde, bunu istatistiksel olarak aynı grupta olan Ecologic çeşidi izlemiştir. En düşük çıkış oranı \% 25.9 ile Barminton çeşidinde saptanmıştır. Çok yıllık çim çeşitlerinin tuz stresine farklı tepki gösterdiği ve bazı çeşitlerinin diğer çeşitlere kıyasla tuzluluğa daha toleranslı olduğu sonucuna varmışlardır (Kuşvuran ve ark., 2015). Tuz stresine bağlı olarak çıkış oranları değerleri \% 1.6 ile \% 77.6 arasında değişmiştir. Artan tuz yoğunluğuna bağlı olarak çıkış oranlarında azalma olduğu belirlenmiştir. Nizam (2011), Lolium perenne 'nin çimlenme oranı bakımında $8 \mathrm{dS} \mathrm{m}^{-1}$ tuzluluk seviyesine kadar toleransa sahip olduğunu, bu seviyeden sonra çimlenme ve gelişmede sorunlar yaşadığını bildirmiştir. Bu çalışmada ise kullanılan tüm çeşitlerde uygulanan tuz yoğunluklarına bağlı olarak çıkış oranında azalma olmuş ancak bu azalmanın çeşitlerde farklılık göstermesi interaksiyonunun önemli çıkmasına neden olmuştur. Bu sonuçlara göre Solstice II ve Ecologic çeşitlerinin tuz stresine daha toleranslı olduğu söylenebilir. Çeşit, kuraklık stresi ve çeşit x kuraklık stresi interaksiyonunun $(p<0.01)$ düzeyinde fide çıkış oranı yönünden önemli olduğu bulunmuştur. Çizelge 1 'de izlendiği gibi çeşitlere bağlı olarak belirlenen ortalama çıkış oranları \% 17.6 ile \% 30.6 arasında değişmiştir. 
Çizelge 1. Çok yıllık çim çeşitlerinde farklı tuz ve kuraklık streslerinin çıkış oranlarına (\%) etkisi Table 1. Effects of different salinity and drought stress on seedling emergence rate (\%) of perennial ryegrass cultivars

Tuz yoğunluk uygulamaları

PEG 6000 uygulamaları

Çeşitler

\begin{tabular}{|c|c|c|c|c|c|c|c|c|c|c|c|}
\hline Tuz & Apple GI & Ecologic & Barm. & Solstice II & Ort. & $\mathrm{MPa}$ & Apple Gl & Ecologic & Barm. & Solstice & Ort. \\
\hline 0 & $76.50 \mathrm{bc}+$ & $82.50 \mathrm{ab}$ & $62.50 \mathrm{bcd}$ & $89.00 \mathrm{a}$ & $77.6 \mathrm{~A}++$ & 0 & $76.0 \mathrm{ab}+$ & $81.0 \mathrm{a}$ & $57.0 \mathrm{~cd}$ & $88.0 \mathrm{a}$ & $75.5 \mathrm{~A}++$ \\
\hline 50 & 52.00 def & $74.50 \mathrm{abc}$ & $27.00 \mathrm{gh}$ & $78.50 \mathrm{ab}$ & $58.0 \mathrm{~B}$ & -0.4 & $51.5 \mathrm{~cd}$ & $62.0 \mathrm{bc}$ & $26.0 \mathrm{e}$ & $47.5 \mathrm{~d}$ & $46.8 \mathrm{~B}$ \\
\hline 100 & 38.50 efg & $42.00 \mathrm{~d}-\mathrm{g}$ & $25.50 \mathrm{ghı}$ & 56.00 cde & $40.5 \mathrm{C}$ & -0.8 & $4.5 \mathrm{f}$ & $6.0 \mathrm{f}$ & $2.0 \mathrm{f}$ & $3.5 \mathrm{ff}$ & $4.0 \mathrm{C}$ \\
\hline 150 & 15.50 hij & $30.50 \mathrm{fgh}$ & زا 14.50 & 26.50 ghı & $21.8 \mathrm{D}$ & -1.2 & $3.0 \mathrm{f}$ & $4.0 \mathrm{f}$ & $3.0 \mathrm{f}$ & $3.5 f$ & $3.4 \mathrm{C}$ \\
\hline 200 & 5.00 ij & $1.50 \mathrm{j}$ & $0.00 \mathrm{j}$ & $0.00 \mathrm{j}$ & $1.6 \mathrm{E}$ & -1.6 & $0.0 \mathrm{f}$ & $0.0 \mathrm{f}$ & $0.0 \mathrm{f}$ & $0.0 \mathrm{f}$ & $0.0 \mathrm{C}$ \\
\hline Ort. & $37.5 \mathrm{~B}+++$ & $46.2 \mathrm{~A}$ & $25.9 \mathrm{C}$ & $50.0 \mathrm{~A}$ & & & $27.0 \mathrm{~A}$ & $30.6 \mathrm{~A}$ & $17.6 \mathrm{~B}$ & $28.5 \mathrm{~A}$ & \\
\hline
\end{tabular}

+ Aynı sütun ve satır içerisinde benzer harfle gösterilen sayılar Tukey testine göre \%5 hata sınırları içerisinde birbirinden farksızdır.

++ Aynı sütun içerisinde benzer harfle gösterilen sayılar Tukey testine göre $\% 5$ hata sınırları içerisinde birbirinden farksızdır.

+++ Aynı satır içerisinde benzer harfle gösterilen sayılar Tukey testine göre $\% 5$ hata sınırları içerisinde birbirinden farksızdır.

Lolium perenne çeşitlerinin kuraklık stresine farklı tepki gösterdiği ve bazı çeşitlerin diğer çeşitlere kıyasla kuraklığa daha toleranslı olduğu sonucuna varmışlardır. Kuraklık stresine bağlı olarak çıkış oranları değerleri \% 0.0 ile \% 75.5 arasında değişmiştir. Artan kuraklık stresine bağlı olarak çıkış oranlarında azalma olduğu belirlenmiştir. Kuraklık stresi arttıkça çimlenme oranının azaldığı $(-0.6 \mathrm{MPa})$ ve $(-1.2 \mathrm{MPa})$ kuraklık uygulamasında bazı türlerde çimlenmenin olmadığı (Rouhi ve ark., 2011; Borawska-Jarmułowicz ve ark., 2017) bildirilmiştir.

Çeşit, tuz yoğunluğu ve çeşit $x$ tuz yoğunluğu interaksiyonunun $(p<0.01)$ düzeyinde fide çıkış indeksi yönünden önemli olduğu bulunmuştur. Çizelge 2 'de izlendiği gibi çeşitlere bağlı olarak belirlenen ortalama çıkış indeksi 1.95 ile 7.01 arasında değişmiştir. En uzun ortalama çıkış indeksi Solstice II çeşidinde bunu Apple GL izlemiş, en erken ortalama çıkış indeksi ise Barminton çeşidinde tespit edilmiştir. Çimlenme indeksinin yüksek olması çimlenme ve çıkış gücünün yüksek olmasına işaret etmekte ve Solstice II çeşidinde çıkış indeksinin yüksek olması tuzluluk stresine daha toleranslı olduğunu söyleyebiliriz. Farklı bitki tür ve çeşitlerle yürütülen araştırmalarda (Turhan ve ark., 2011; Atak ve Mavi, 2016; Ertekin ve ark., 2017) tuz stresine farklı tür ve çeşitler çimlenme indeksi bakımından farklı tepki gösterdikleri bildirmişlerdir. Artan tuz yoğunluğuna bağlı olarak çıkış indeksinde azalma olduğu, çıkış indeksi 0.09 ile 9.67 arasında değiştiği tespit edilmiştir. Kontrol uygulamasında 9.67, (50 mM) tuz yoğunluğunda 7.11 ancak tuz yoğunluğu arttıkça çimlenme indeksi (100 mM) 2,94, (150 mM) 1.29 ve (200 mM) 0.09 ile \% 5'in altına düştüğü bulunmuştur. Nizam (2011), çok yıllık çimin çimlenme oranı bakımında $8 \mathrm{dS} \mathrm{m}^{-1}$ tuzluluk seviyesine kadar toleransa sahip olduğunu, bu seviyeden sonra çimlenme ve gelişmede sorunlar yaşadığını bildirmiştir.

Çizelge 2. Çok yıllık çim çeşitlerinde farklı tuz ve kuraklık streslerinin çıkış indeksine etkisi Table 2. Effects of different salinity and drought stress on seedling emergence index of perennial ryegrass cultivars

\begin{tabular}{|c|c|c|c|c|c|c|c|c|c|c|c|}
\hline \multicolumn{5}{|c|}{ Tuz yoğunluk uygulamaları } & \multicolumn{7}{|c|}{ PEG 6000 uygulamaları } \\
\hline \multirow[b]{2}{*}{ Tuz } & \multicolumn{3}{|c|}{ Çeşitler } & \multirow[b]{2}{*}{ Solstice } & \multicolumn{7}{|c|}{ Çeşitler } \\
\hline & Apple GI & Ecologic & Barm. & & Ort. & $\mathrm{MPa}$ & Apple Gl & Ecologic & Barm. & Solstice & Ort. \\
\hline 0 & $9.95 b+$ & $8.50 \mathrm{bc}$ & 5.13 def & $15.08 \mathrm{a}$ & $9.67 \mathrm{~A}++$ & 0 & $10.0 \mathrm{~b}+$ & $8.5 \mathrm{bc}$ & $5.1 \mathrm{~d}$ & $15.1 \mathrm{a}$ & $9.7 \mathrm{~A}++$ \\
\hline 50 & 5.74 cde & $5.98 \mathrm{~cd}$ & $2.31 \mathrm{f}-\mathrm{j}$ & $14.40 \mathrm{a}$ & $7.11 \mathrm{~B}$ & -0.4 & $6.7 \mathrm{~cd}$ & $8.8 \mathrm{bc}$ & $2.7 \mathrm{e}$ & $6.6 \mathrm{~cd}$ & $6.2 \mathrm{~B}$ \\
\hline 100 & $3.29 \mathrm{~d}-\mathrm{h}$ & $2.98 \mathrm{e}-1$ & $1.48 \mathrm{~g}-\mathrm{j}$ & $4.01 \mathrm{~d}-\mathrm{g}$ & $2.94 \mathrm{C}$ & -0.8 & 0.5 ef & 0.6 ef & $0.2 \mathrm{f}$ & $0.3 \mathrm{f}$ & $0.4 \mathrm{C}$ \\
\hline 150 & 1.05 hij & $1.74 \mathrm{~g}-\mathrm{j}$ & 0.83 hij & $1.54 \mathrm{~g}-\mathrm{j}$ & $1.29 \mathrm{D}$ & -1.2 & $0.3 \mathrm{f}$ & 0.4 ef & $0.3 \mathrm{f}$ & 0.4 ef & $0.3 \mathrm{C}$ \\
\hline 200 & 0.27 & $0.09 \mathrm{j}$ & $0.00 \mathrm{j}$ & $0.00 \mathrm{j}$ & $0.09 \mathrm{E}$ & -1.6 & $0.0 \mathrm{f}$ & $0.0 \mathrm{f}$ & $0.0 \mathrm{f}$ & $0.0 \mathrm{f}$ & $0.0 \mathrm{C}$ \\
\hline Ort. & $4.06 \mathrm{~B}+++$ & $3.86 \mathrm{~B}$ & $1.95 \mathrm{C}$ & $7.01 \mathrm{~A}$ & & & $3.5 \mathrm{~B}+++$ & $3.7 \mathrm{~B}$ & $1.7 \mathrm{C}$ & $4.5 \mathrm{~A}$ & \\
\hline
\end{tabular}

+ Aynı sütun ve satır içerisinde benzer harfle gösterilen sayılar Tukey testine göre $\% 5$ hata sınırları içerisinde birbirinden farksızdır.

++ Aynı sütun içerisinde benzer harfle gösterilen sayılar Tukey testine göre \%5 hata sınırları içerisinde birbirinden farksızdır.

+++ Aynı satır içerisinde benzer harfle gösterilen sayılar Tukey testine göre \%5 hata sınırları içerisinde birbirinden farksızdır. 
Çeşit, kuraklık stresi ve çeşit $\mathrm{x}$ kuraklık stresi interaksiyonunun $(p<0.01)$ fide çıkış indeksi yönünden önemli olduğu bulunmuştur. Çizelge 2 'de izlendiği gibi çeşitlere bağlı olarak belirlenen ortalama çimlenme indeksi 1.7 ile 4.5 arasında değişmiştir. En yüksek fide çıkış indeksi Solstice II çeşidinde, bunu istatistiksel olarak farklı grupta olan Ecologic ve Apple GL çeşitleri izlemiştir. En düşük fide çıkış indeksi 1.7 ile Barminton çeşidinde olduğu tespit edilmiştir. Çıkış indeksi ile ilgili bulgularımız buğdayda kuraklık stresi araştırması yapan Bilgili ve ark. (2019)'in bulgularıyla paralellik göstermektedir. Kuraklığa bağlı olarak fide çıkış indeksi 0.0 ile \% 9.7 arasında değişmiştir. Artan kuraklık stresine bağlı olarak çimlenme indeksinde azalma olduğu hatta (-1.6 MPa) kuraklık stresinde hiç çimlenme olmadığı tespit edilmiştir. Balkan ve Gençtan (2013) buğdayda yapmış oldukları araştırmada (-1.6 $\mathrm{MPa}$ ) stres uygulamasında çimlenmenin oluşmadığını bildirmişlerdir. Fide çıkış indeksindeki düşüş tohumların hem oransal olarak çimlenme yeteneğinin azaldığını hem de fide çıkış süresinin arttığını gösterir. Bu çalışmada kullanılan çeşitleri uygulanan kuraklık stresine bağlı olarak fide çıkış indeksinde azalma olmakta ve bu azalma istatistiksel olarak farklılık göstermesi interaksiyonunun önemli çıkmasına neden olmuştur.

Çeşitlerin önemsiz ancak, tuz yoğunluğu ve çeşit $x$ tuz yoğunluğu interaksiyonunun $(p<0.01)$ fide kök uzunluğu yönünden önemli olduğu bulunmuştur. Çizelge $3^{\prime}$ de izlendiği gibi çeşitlere bağlı olarak belirlenen ortalama kök uzunluğu 14.20 ile 16.00 arasında değişmiştir. En yüksek kök uzunluğu Solstice II çeşidinde, en düşük kök uzunluğu ise Apple GL çeşidinde tespit edilmiştir. Artan tuz yoğunluğuna bağlı olarak kök uzunluğu (100 mM) tuz yoğunluğuna kadar arttığı (150 mM) uygulamasında azalmakta ancak artış ve azalış istatistiksel olarak farklılık oluşturmamaktadır. Ancak (200 mM) uygulaması istatistiksel olarak önemli olup farklı grupta yer almıştır. Farklı Lolium perenne L., kamışsı yumak (Festuca arundinacea Scheb.) ve kırmızı yumak (Festuca rubra L.) tür ve çeşitleriyle yapılan araştırmalarda kontrol uygulamaya göre artan tuz yoğunluğunda kök uzunluğunda artış olduğu ancak daha sonra tuzluluk arttıkça kök uzunluğunda azalma olduğu bildirilmiştir (Kuşvuran ve ark., 2014a; Kuşvuran ve ark., 2014b Kuşvuran ve ark., 2015; Zhang ve ark., 2012).

Çizelge 3. Çok yıllık çim çeşitlerinde farklı tuz ve kuraklık streslerinin fide kök uzunluğuna $(\mathrm{mm})$ etkisi Table 3. Effects of different salinity and drought stress on seedling root length $(\mathrm{mm})$ of perennial ryegrass cultivars

\begin{tabular}{|c|c|c|c|c|c|c|c|c|c|c|c|}
\hline & & uz yoğunlu & < uygulamalar & & & & & PEG 6000 & ygulama & & \\
\hline & & Çeşitler & & & & & & Çeşitler & & & \\
\hline Tuz & Apple GI & Ecologic & Barminton & Solstice II & Ort. & $\mathrm{MPa}$ & Apple GI & Ecologic & Barm. & Solstıce II & Ort. \\
\hline 0 & $13.48 \mathrm{bc}+$ & $21.18 \mathrm{ab}$ & $19.78 \mathrm{ab}$ & $18.68 \mathrm{ab}$ & $18.28 \mathrm{~A}++$ & 0 & 13.48 & 21.18 & 19.78 & 18.68 & $18.28 \mathrm{C}++$ \\
\hline 50 & $15.80 \mathrm{abc}$ & $22.20 \mathrm{ab}$ & $18.64 \mathrm{ab}$ & $17.68 \mathrm{abc}$ & $18.58 \mathrm{~A}$ & -0.4 & 35.18 & 42.08 & 33.96 & 37.80 & $37.25 \mathrm{~A}$ \\
\hline 100 & $18.55 a b$ & $20.10 a b$ & $19.22 \mathrm{ab}$ & $24.25 \mathrm{a}$ & $20.53 \mathrm{~A}$ & -0.8 & 28.42 & 28.54 & 29.50 & 28.83 & $28.82 \mathrm{~B}$ \\
\hline 150 & $14.33 \mathrm{bc}$ & $15.99 \mathrm{abc}$ & $21.47 \mathrm{ab}$ & $19.38 \mathrm{ab}$ & $17.79 \mathrm{~A}$ & -1.2 & 5.19 & 5.88 & 9.92 & 18.67 & $9.91 \mathrm{D}$ \\
\hline 200 & $8.84 \mathrm{~cd}$ & $2.75 \mathrm{~d}$ & $0.00 \mathrm{~d}$ & $0.00 \mathrm{~d}$ & $2.90 \mathrm{~B}$ & -1.6 & 0.00 & 0.00 & 0.00 & 0.00 & $0.00 \mathrm{E}$ \\
\hline Ort. & 14.20 & 16.44 & 15.82 & 16.00 & & & 16.45 & 19.53 & 18.63 & 20.80 & \\
\hline
\end{tabular}

+ Aynı sütun ve satır içerisinde benzer harfle gösterilen sayılar Tukey testine göre $\% 5$ hata sınırları içerisinde birbirinden farksızdır. ++ Aynı sütun içerisinde benzer harfle gösterilen sayılar Tukey testine göre \%5 hata sınırları içerisinde birbirinden farksızdır.

Çeşit ve çeşit x kuraklık stresi interaksiyonunun önemsiz ancak kuraklık stresi $(p<0.01)$ fide kök uzunluğu yönünden önemli olduğu bulunmuştur. Çizelge 3 'de izlendiği gibi çeşitlere bağlı olarak belirlenen kök uzunluğu 16.45 ile 20.80 arasında değişmiştir. En yüksek kök uzunluğu Solstice II çeşidinde en düşük kök uzunluğu 16.45 ile Apple GL çeşidinde bulunmuş olup kök uzunluğu açısından istatistiksel fark bulunmadığı tespit edilmiştir. Artan kuraklık stresine bağlı olarak kök uzunluğu (-0.4MPa) ve (-0.8 $\mathrm{MPa})$ uygulamalarında artış olduğu, (-1.2 $\mathrm{MPa})$ uygulamasında kök uzunluğunda azalma olduğu fakat (-1.6 $\mathrm{MPa})$ kuraklık stresinde hiç çimlenme olmadığı tespit edilmiştir. Kuraklık stresine bağlı olarak kontrole göre kök uzunluğunun Radhouane (2007) inci darısında yapmış olduğu araştırmada kontrole göre $(-1.0 \mathrm{MPa})$ kuraklık stresinde kök uzunluğunun arttığı ancak (-2.0 $\mathrm{MPa})$ kuraklık uygulamasında kök uzunluğunun azaldığını bildirmişlerdir. Kuraklık stresindeki artış kök uzunluğunda önce artışa sonra azalmaya neden olmuştur. Benzer bulgular (Berg ve Zeng, 2006; Khodarahmpour, 2011; Balkan ve Gençtan, 2013; Borawska-Jarmułowicz ve ark., 2017; Zhang ve ark., 2018) tarafından bildirilmiştir. 
Çeşit, tuz yoğunluğu ve çeşit $x$ tuz yoğunluğu interaksiyonunun $(p<0.01)$ düzeyinde fide sap uzunluğu yönünden önemli olduğu bulunmuştur. Çizelge 4.'de verilmiştir. Çeşitlere bağı ı olarak belirlenen ortalama sap uzunluğu 42.45 ile 50.86 arasında değişmiştir. En yüksek sap uzunluğu Solstice II çeşidinde, en düşük sap uzunluğu ise Apple GL çeşidinde tespit edilmiştir. Farklı bitki tür ve çeşitlerle yürütülen araştırmalarda (Kuşvuran ve ark., 2014b; Kuşvuran ve ark., 2015 ve Topcu ve ark., 2016) tuz stresine farklı tür ve çeşitler sap uzunluğu bakımından farklı tepki gösterdikleri bildirmişlerdir. Artan tuz yoğunluğuna bağlı olarak sap uzunluğu azalma olduğu (Nizam, 2011 Kuşvuran ve ark., 2014a; Kuşvuran ve ark., 2014b; Hokmalipour, 2015; Aşçı ve Üney, 2016; Topcu ve ark., 2016; Borawska-Jarmułowicz ve ark., 2017) belirlenmiştir.

Çizelge 4. Çok yıllık çim çeşitlerinde farklı tuz ve kuraklık streslerinin fide sap uzunluğuna $(\mathrm{mm})$ etkisi Table 4. Effects of different salinity and drought stress on seedling shoot length $(\mathrm{mm})$ of perennial ryegrass cultivars

\begin{tabular}{|c|c|c|c|c|c|c|c|c|c|c|c|}
\hline \multirow[b]{2}{*}{ Tuz } & \multicolumn{3}{|c|}{$\begin{array}{l}\text { Tuz yoğunluk uygulamaları } \\
\text { Çeşitler }\end{array}$} & \multirow[b]{2}{*}{ Solstıce II } & \multirow[b]{2}{*}{ Ort. } & \multicolumn{6}{|c|}{$\begin{array}{l}\text { PEG } 6000 \text { uygulamaları } \\
\text { Çeşitler }\end{array}$} \\
\hline & Apple GI & Ecologıc & Barmınton & & & $\mathrm{MPa}$ & Apple Gl & EcologIC & Barmınton & Solstice II & Ort. \\
\hline 0 & 53.85 def+ & $81.05 \mathrm{a}$ & $79.35 \mathrm{ab}$ & $78.98 \mathrm{ab}$ & 73.31A++ & 0 & $53.85 b-f+$ & $81.05 a b$ & $79.35 a b$ & $78.98 a b$ & $73.31 \mathrm{~A}++$ \\
\hline 50 & $61.95 \mathrm{bcd}$ & $67.80 a-d$ & $73.79 a b c$ & 83.68 a & $71.80 \mathrm{~A}$ & -0.4 & $65.83 \mathrm{abc}$ & $85.53 \mathrm{a}$ & 62.02 a-e & $64.20 \mathrm{a}-\mathrm{d}$ & $69.39 \mathrm{~A}$ \\
\hline 100 & $50.69 \mathrm{~d}-\mathrm{g}$ & $53.10 \mathrm{~d}-\mathrm{g}$ & 39.49 e-h & 56.73 cde & $50.00 \mathrm{~B}$ & -0.8 & $44.54 \mathrm{c}-\mathrm{f}$ & $36.92 \mathrm{~d}-\mathrm{g}$ & $32.25 \mathrm{f}-\mathrm{I}$ & 34.75 e-h & $37.12 \mathrm{~B}$ \\
\hline 150 & $36.16 \mathrm{fgh}$ & $31.79 \mathrm{~h}$ & $38.06 \mathrm{fgh}$ & $34.92 \mathrm{gh}$ & $35.23 \mathrm{C}$ & -1.2 & 6.69 hij & $6.50 \mathrm{ij}$ & $14.67 \mathrm{~g}-\mathrm{j}$ & $28.63 \mathrm{f}-\mathrm{I}$ & $14.12 \mathrm{C}$ \\
\hline 200 & 9.58 I & 7.251 & 0.00 I & 0.00 I & $4.21 \mathrm{D}$ & -1.6 & $0.00 \mathrm{j}$ & $0.00 \mathrm{j}$ & $0.00 \mathrm{j}$ & $0.00 \mathrm{j}$ & $0.00 \mathrm{D}$ \\
\hline Ort. & $42.45 \mathrm{~B}+++$ & $48.20 \mathrm{AB}$ & $46.14 \mathrm{AB}$ & $50.86 \mathrm{~A}$ & & & 34.18 & 42.00 & 37.66 & 41.31 & \\
\hline
\end{tabular}

+ Aynı sütun ve satır içerisinde benzer harfle gösterilen sayılar Tukey testine göre $\% 5$ hata sınırları içerisinde birbirinden farksızdır.

++ Aynı sütun içerisinde benzer harfle gösterilen sayılar Tukey testine göre $\% 5$ hata sınırları içerisinde birbirinden farksızdır.

+++ Aynı satır içerisinde benzer harfle gösterilen sayılar Tukey testine göre $\% 5$ hata sınırları içerisinde birbirinden farksızdır.

Çeşitlerin önemsiz ancak, kuraklık stresi ve çeşit $x$ kuraklık stresi interaksiyonu $(p<0.01)$ fide sap uzunluğu yönünden önemli olduğu bulunmuştur. Çizelge 4 'de izlendiği gibi çeşitlere bağlı olarak belirlenen ortalama sap uzunluğu 34.18 ile 42.00 arasında değişmiştir. En yüksek sap uzunluğu Ecologıc çeşidinde, en düşük sap uzunluğu 34.18 ile Apple GL çeşidinde bulunmuş olup fide uzunluğu açısından istatistiksel fark bulunmadığı tespit edilmiştir. Artan kuraklık stresine bağlı olarak sap uzunluğu $(-0.8 \mathrm{MPa}),(-1.2 \mathrm{MPa})$ uygulamasına kadar azalma olduğu, (-1.6 MPa) kuraklık stresinde hiç çıkış olmadığı tespit edilmiştir. Kuraklık stresindeki artış sap uzunluğunda azalmaya neden olmuştur. Benzer bulgular bazı araştırıcılar (Khodarahmpour, 2011; Balkan ve Gençtan, 2013; Borawska-Jarmułowıcz ve ark., 2017) tarafından bildirilmiştir. Çeşitlerin uygulanan kuraklık stresine sap uzunluğu bakımından farklı tepki göstermesi interaksiyonunun önemli çıkmasına neden olmuştur.

Çeşit, tuz yoğunluğu ve çeşit $x$ tuz yoğunluğu interaksiyonunun $(p<0.01)$ düzeyinde fide kök yaş ağırlığı yönünden önemli olduğu bulunmuştur. Çizelge 5 'de verilmiştir. Ortalama kök yaş ağırlıklara 4.80 ile 8.32 arasında değişmiştir. En yüksek kök yaş ağırlıklara Solstice II çeşidinde, en düşük kök yaş ağırlıklara ise Apple GL çeşidinde tespit edilmiştir. Farklı bitki tür ve çeşitlerle yürütülen araştırmalarda (Kuşvuran ve ark., 2014a; Kuşvuran ve ark., 2014b; Kuşvuran ve ark., 2015; Topcu ve ark., 2016; Ertekin ve ark., 2018; Beyazçiçek ve Yılmaz, 2020) tuz stresine farklı tür ve çeşitler kök ağırlıkları bakımından farklı tepki gösterdikleri bildirmişlerdir. Artan tuz yoğunluğuna bağlı olarak kök yaş ağırlıklara azalma olduğu ancak $(150 \mathrm{mM})$ tuz yoğunluğuna kadarki azalma istatistiksel olarak farklılık göstermemiştir. Önceki yapılan çalışmalarda (Khayatnezhad ve Gholamin, 2011; Hokmalipour, 2015; Topcu ve ark., 2016; Ertekin ve ark., 2018) tuz stresi arttıkça kök yaş ağırlığında azalma olduğu bildirilmiştir.

Çeşit, kuraklık stresi ve çeşit $x$ kuraklık stresi interaksiyonunun $(p<0.01)$ fide kök yaş ağırlığı yönünden önemli olduğu bulunmuştur. Çeşitlere bağlı olarak belirlenen kök yaş ağırlığı 2.92 ile 5.93 arasında değişmiştir. En yüksek kök yaş ağırığı Solstice II çeşidinde, en düşük kök yaş ağırlığı 2.92 ile Apple GL çeşidinde bulunmuştur. Farklı bitki tür ve çeşitlerle yürütülen araştırmalarda (Rouhi ve ark., 2011; Bilgili ve ark., 2019) kuraklık stresinin farklı tür ve çeşitlerde kök yaş ağırlığı bakımından farklı tepki gösterdiklerini bildirmişlerdir. Artan kuraklık stresine bağlı olarak kök yaş ağırlığında azalma olmuştur. Rouhi ve ark. (2011) kuraklık stresi araştırmasında (-1.2 MPa) uygulamasında ve buğdayda da (-1.6 $\mathrm{MPa})$ stres uygulamasında çimlenmenin oluşmadığını (Balkan ve Gençtan 2013) bildirmişlerdir. Farklı bitki tür ve çeşitlerle yürütülen araştırmalarda (Kaya ve ark., 2006; Khayatnezhad ve Gholamin, 2011; Castroluna ve ark., 2014; Bilgili ve ark., 2019) kuraklık stresinin farklı tür ve çeşitlerde kök yaş ağırlığına farklı tepki gösterdiklerini bildirmişlerdir. Çeşitlerin uygulanan kuraklık stresine fide kök yaş ağırlığı 
bakımından farklı tepki göstermesi interaksiyonunun önemli çıkmasına neden olmuştur. Çeşit, tuz yoğunluğu ve çeşit $x$ tuz yoğunluğu interaksiyonunun $(p<0.01)$ düzeyinde fide sap yaş ağırlığı yönünden önemli olduğu bulunmuştur.

Çizelge 5. Çok yıllık çim çeşitlerinde farklı tuz ve kuraklık streslerinin fide kök yaş ağırlığına (mg bitki ${ }^{-1}$ ) etkisi Table 5. Effects of different salinity and drought stress on seedling root fresh weight $\left(\mathrm{mg} \mathrm{plant}^{-1}\right)$ of some perennial ryegrass cultivars

\begin{tabular}{|c|c|c|c|c|c|c|c|c|c|c|c|}
\hline \multirow[b]{2}{*}{ Tuz } & \multirow[b]{2}{*}{ Apple GI } & \multicolumn{3}{|c|}{$\begin{array}{l}\text { Tuz yoğunluk uygulamaları } \\
\text { Çeşitler }\end{array}$} & \multirow[b]{2}{*}{ Ort. } & \multicolumn{6}{|c|}{$\begin{array}{l}\text { PEG } 6000 \text { uygulamaları } \\
\text { Çeşitler }\end{array}$} \\
\hline & & Ecologic & Barminton & Solstice II & & $\mathrm{MPa}$ & Apple Gl & Ecologic & Barminton & Solstice II & Ort. \\
\hline 0 & 5,01 efg+ & $8,85 \mathrm{bcd}$ & 5,49 def & $12,59 \mathrm{a}$ & 7,98 A++ & 0 & $5.01 \mathrm{~cd} \mathrm{e}+$ & $8.85 \mathrm{abc}$ & $7.40 \mathrm{bcd}$ & $12.59 \mathrm{a}$ & $8.46 \mathrm{~A}++$ \\
\hline 50 & $6,75 \mathrm{cde}$ & 6,98 b-e & 5,57 def & $10,46 a b$ & 7,44 A & -0.4 & $5.05 \mathrm{cde}$ & $5.17 \mathrm{cde}$ & $5.49 \mathrm{cde}$ & $9.68 \mathrm{ab}$ & $6.35 \mathrm{AB}$ \\
\hline 100 & 5,01 efg & 7,24 b-e & 5,85 def & 9,05 a-d & $6,79 \mathrm{~A}$ & -0.8 & $3.77 \mathrm{~d}-\mathrm{g}$ & $5.16 \mathrm{cde}$ & $4.67 \mathrm{def}$ & $4.95 \mathrm{cde}$ & $4.64 \mathrm{~B}$ \\
\hline 150 & 4,73 efg & 5,71def & 7,86 b-e & $9,51 \mathrm{abc}$ & $6,95 \mathrm{~A}$ & -1.2 & $0.78 \mathrm{fg}$ & $0.76 \mathrm{fg}$ & 3.03 efg & $2.43 \mathrm{efg}$ & $1.75 \mathrm{C}$ \\
\hline 200 & $2,50 \mathrm{fgh}$ & $1,75 \mathrm{gh}$ & $0,00 \mathrm{~h}$ & $0,00 \mathrm{~h}$ & $1,06 \mathrm{~B}$ & -1.6 & $0.00 \mathrm{~g}$ & $0.00 \mathrm{~g}$ & $0.00 \mathrm{~g}$ & $0.00 \mathrm{~g}$ & $0.00 \mathrm{D}$ \\
\hline Ort. & $4,80 \mathrm{C}+++$ & $6,10 \mathrm{~B}$ & $4,95 \mathrm{BC}$ & $8,32 \mathrm{~A}$ & & & $2.92 \mathrm{~B}+++$ & $3.99 \mathrm{~B}$ & $4.12 \mathrm{~B}$ & $5.93 \mathrm{~A}$ & \\
\hline
\end{tabular}

+ Aynı sütun ve satır içerisinde benzer harfle gösterilen sayılar Tukey testine göre $\% 5$ hata sınırları içerisinde birbirinden farksızdır. ++ Aynı sütun içerisinde benzer harfle gösterilen sayılar Tukey testine göre $\% 5$ hata sınırları içerisinde birbirinden farksızdır.

+++ Aynı satır içerisinde benzer harfle gösterilen sayılar Tukey testine göre $\% 5$ hata sınırları içerisinde birbirinden farksızdır.

Çeşitlere bağlı olarak belirlenen ortalama sap yaş ağırlıklar 5.333 ile 7.309 arasında değişmiştir. En yüksek sap yaş ağırlıklara Solstice II çeşidinde, en düşük fide sap yaş ağırlığı ise Apple GL çeşidinde tespit edilmiştir. Farklı bitki tür ve çeşitlerle yürütülen araştırmalarda (Khayatnezhad ve Gholamin, 2011; Kuşvuran ve ark., 2015; Topcu ve ark., 2016) tuz stresine farklı tür ve çeşitler fide sap yaş ağırlıkları bakımından farklı tepki gösterdikleri bildirmişlerdir. Artan tuz yoğunluğuna bağıı olarak sap yaş ağırlıklara azalma olduğu tespit edilmiştir. Bitki türlerini tuz yoğunluğuna tepkileri birbirinden oldukça farklılık gösterdiği, hatta aynı türün çeşitleri arasında farklılıklar gösterdiği (Nizam 2011; Castroluna ve ark., 2014; Kuşvuran ve ark., 2015; Aş̧ı ve Üney 2016) artan tuz stresine bağlı olarak sap yaş ağırlığında azalma olduğu belirlenmiştir.

Çizelge 6. Çok yıllık çim çeşitlerinde farklı tuz ve kuraklık streslerinin fide sap yaş ağırlığına $\left(\mathrm{mg} \mathrm{bitki}^{-1}\right)$ etkisi Table 6. Effects of different salinity and drought stress on seedling shoot fresh weight (mg plant $\left.{ }^{-1}\right)$ of some perennial ryegrass cultivars

\begin{tabular}{|c|c|c|c|c|c|c|c|c|c|c|c|}
\hline \multirow[b]{2}{*}{ Tuz } & \multicolumn{4}{|c|}{$\begin{array}{l}\text { Tuz yoğunluk uygulamaları } \\
\text { Çeşitler }\end{array}$} & \multirow[b]{2}{*}{ Ort. } & \multicolumn{6}{|c|}{$\begin{array}{l}\text { PEG } 6000 \text { uygulamaları } \\
\text { Çeşitler }\end{array}$} \\
\hline & Apple GI & Ecologic & Barminton & Solstice II & & $\mathrm{MPa}$ & Apple GI & Ecologic & Barminton & Solstice II & Ort. \\
\hline 0 & $6.983 \mathrm{cde}+$ & $11.368 \mathrm{a}$ & $10.500 \mathrm{ab}$ & $13.153 \mathrm{a}$ & $10.5 \mathrm{~A}++$ & 0 & $6.98 \mathrm{~cd}+$ & $11.37 \mathrm{ab}$ & $10.50 \mathrm{abc}$ & $13.15 \mathrm{a}$ & $10.50 \mathrm{~A}++$ \\
\hline 50 & 7.035 cde & $8.213 b c$ & $7.343 \mathrm{~cd}$ & $11.080 \mathrm{ab}$ & $8.418 \mathrm{~B}$ & -0.4 & $4.70 \mathrm{def}$ & 6.63 cde & $7.15 \mathrm{bcd}$ & $7.04 \mathrm{~cd}$ & $6.38 \mathrm{~B}$ \\
\hline 100 & $6.740 \mathrm{cde}$ & $6.738 \mathrm{cde}$ & $5.610 \mathrm{cde}$ & $6.848 \mathrm{cde}$ & $6.484 \mathrm{C}$ & -0.8 & $4.27 \mathrm{def}$ & 4.59 def & $4.56 \mathrm{def}$ & $5.74 \mathrm{de}$ & $4.79 \mathrm{BC}$ \\
\hline 150 & 4.350 def & 4.158 ef & 4.443 def & $5.463 \mathrm{cde}$ & $4.603 \mathrm{D}$ & -1.2 & $0.61 \mathrm{fg}$ & $1.13 \mathrm{fg}$ & 2.44 efg & $4.53 \mathrm{def}$ & $2.18 \mathrm{C}$ \\
\hline 200 & $1.558 \mathrm{fg}$ & $0.925 \mathrm{~g}$ & $0.000 \mathrm{~g}$ & $0.000 \mathrm{~g}$ & $0.621 \mathrm{E}$ & -1.6 & $0.00 \mathrm{~g}$ & $0.00 \mathrm{~g}$ & $0.00 \mathrm{~g}$ & $0.00 \mathrm{~g}$ & $0.00 \mathrm{D}$ \\
\hline Ort. & $5.333 \mathrm{~B}+++$ & $6.280 \mathrm{~B}$ & $5.579 \mathrm{~B}$ & $7.309 \mathrm{~A}$ & & & $3.31 \mathrm{~B}+++$ & $4.74 \mathrm{~A}$ & $4.93 \mathrm{~A}$ & $6.09 \mathrm{~A}$ & \\
\hline
\end{tabular}

+ Aynı sütun ve satır içerisinde benzer harfle gösterilen sayılar Tukey testine göre $\% 5$ hata sınırları içerisinde birbirinden farksızdır.

++ Aynı sütun içerisinde benzer harfle gösterilen sayılar Tukey testine göre \%5 hata sınırları içerisinde birbirinden farksızdır.

+++ Aynı satır içerisinde benzer harfle gösterilen sayılar Tukey testine göre $\% 5$ hata sınırları içerisinde birbirinden farksızdır.

Çeşit, kuraklık stresi ve çeşit $x$ kuraklık stresi interaksiyonunun $(p<0.01)$ fide sap yaş ağırlığı yönünden önemli olduğu bulunmuştur. Çeşitlere bağlı olarak belirlenen sap yaş ağırlığı 3.31 ile 6.09 arasında değişmiştir. En yüksek sap yaş ağırlı̆̆ı Solstice II çeşidinde olmuş bunu istatistiksel olarak farklı olmayan Barminton ve Ecologic çeşitleri izlemiş en düşük sap yaş ağırlığı 3.31 ile Apple GL çeşidinde bulunmuştur. Farklı bitki tür ve çeşitlerle yürütülen araştırmalarda (Rouhi ve ark., 2011;
Ahmad ve ark., 2014) kuraklık stresine, farklı tür ve çeşitler sap yaş ağırlığına farklı tepki gösterdiklerini bildirmişlerdir. Artan kuraklık stresine bağlı olarak sap yaş ağırlı̆ıında azalma olmuştur. Farklı bitki tür ve çeşitlerle yürütülen araştırmalarda Khodarahmpour, 2011; Rouhi ve ark., 2011; Balkan ve Gençtan, 2013; Castroluna ve ark., 2014; Çarpıcı ve Erdel, 2015) kuraklık stresine fide sap yaş ağırlığı bakımından farklı tür ve çeşitlerde farklı tepki gösterdiklerini bildirmişlerdir. 
Çeşitlerin uygulanan kuraklık stresine sap yaş ağırlığı bakımından farklı tepki göstermesi interaksiyonunun önemli çıkmasına neden olmuştur.

Sonuç olarak, incelenen tüm özellikler artan tuz konsantrasyon ve kuraklık stresi düzeylerinden olumsuz etkilendiği ve bu etkinin istatistiksel olarak önemli olduğu belirlenmiştir. Lolium perenne çeşitlerinin tuz ve kuraklık stresine gösterdikleri tepki faklı olmuştur. Araştırma sonucunda tuzlu ve kurak koşullarda daha iyi çıkış ve fide gelişimi gösteren SOLSTIC II çeşidinin tuzlu ve kurak koşullarda tercih edilebileceği belirlenmiştir. Karışımda ya da saf olarak Lolium perenne Solstice II çeşidi tuz stresi ya da kuraklık stresi olan alanlarda bu olumsuzluğu nispeten ortadan kaldırılabilecektir. Araştırma da kullanılan metot ile kısa sürede çeşitlerin tuzluluk ve kuraklık streslerine toleranslarının belirlenebileceği çalışmanın diğer önemli bir sonucudur.

\section{ÖZET}

Amaç: Bu çalışma, Lolium perenne çeşitlerinin fide gelişim aşamalarında tuz ve kuraklık stresine tepkisini belirlemek amacıyla yapılmıştır.

Yöntem ve Bulgular: Tohum materyali olarak dört çok yıllık çim çeşidi (Apple GL, Ecologic, Barminton ve Solstice II) kullanılmıştır. Lolium perenne çeşitlerinde fide gelişim aşamalarında tuz $(0,50,100,150$ ve $200 \mathrm{mM}$ $\mathrm{NaCl})$ ve kuraklık $(0,-0.4,-0.8,-1.2$. ve $-1.6 \mathrm{MPa}$, PEG6000 ) stresi oluşturmak için beş farklı dozda sodyum klorür ve polietilen glikol kullanılmıştır. Fide gelişimi denemeleri tesadüf parselleri deneme deseninde faktöriyel düzende 4 tekrarlamalı olarak yürütülmüştür. Lolium Perenne çeşitlerinin fide gelişimi, tuz ve kuraklık stresine toleransları araştırılmıştır. Araştırma sonucunda tuz uygulamasında fide kök uzunluğu hariç tüm özelliklerde çeşit, tuz stresi ve çeşit $x$ tuz stresi interaksiyonların önemli olduğu belirlenmiştir. Kuraklık uygulamasında fide kök uzunluğu ve fide sap uzunluğu hariç tüm özelliklerde çeşit $x$ PEG interaksiyonların önemli olduğu belirlenmiştir. Genellikle tuz ve kuraklık stresi arttıkça incelenen özelliklerde önemli azalma olduğu ortaya konmuştur.

Genel Yorum: Lolium perenne çeşitlerinin fide gelişimi incelenen özelliklere göre, farklı oranda tepkiler vermiştir. Tuz'un ve PEG-6000'in Lolium perenne fide gelişiminde kuraklık stresi yaratmada yararlı bir ajan olduğu sonucuna varılabilir, ancak Lolium perenne tuz ve kuraklık stres toleransını daha iyi belirlemek için (150 $\mathrm{mM}$ )tuz ve (-1.2 MPa)'dan daha düşük ozmotik potansiyeller uygulanmalıdır.

Çalışmanın Önemi ve Etkisi: Küresel ısınmanın etkilerini giderek hissedildiği günümüzde kuraklık sorunu ve alternatif su kaynaklarının kullanımına toleranslı tür ve çeşitlerin belirlenmesi çok önemli olacaktır. Kuraklık ve tuzluluk problemine toleranslı tür ve çeşitlerin kısa dönemde belirlenmesi de ayrıca önem taşımaktadır. 21 gün gibi kısa bir çalışma süreci ile yeşil alanlarda kullanılabilecek çeşitlerin test edilmesi tuzluluğa veya kurağa dayanıklı ya da toleranslı çeşidin belirlenmesi çim alanların sürdürülebilirliği açısından önem arz etmektedir.

Anahtar Kelimeler: Çıkış oranı, çok yıllık çim, kuraklık, tuzluluk.

\section{TEŞEKKÜR}

$\mathrm{Bu}$ makale Kahramanmaraş Sütçü İmam Üniversitesi Bilimsel Araştırma Projeleri (BAP) Koordinatörlügü̈nün 2018/1-17 YLS nolu projesi tarafından desteklenmiştir.

\section{ÇIKAR ÇATIŞMA BEYANI}

Yazar(lar) çalışma konusunda çıkar çatışmasının olmadığını beyan eder.

\section{ARAŞTIRMACILARIN KATKI ORANI BEYANI}

Yazarlar çalışmaya eşit oranda katkı sağlamış olduklarını beyan eder.

\section{KAYNAKLAR}

Ahmad S, Ahmad, R, Ashraf MY, Waraich EA (2009) Sunflower (Helianthus annuus L.) response to drought stress at germination and seedling growth stages. Pakistan J. Bot. 41: 647-654.

Akıncı IE, Çalışkan Ü (2010) Kurşunun Bazı Yazlık Sebzelerde Tohum Çimlenmesi ve Tolerans Düzeyleri Üzerine Etkisi. Ekoloji 19(74): 164-172.

Aşcı ÖÖ (2011) Salt tolerance in red clover (Trifolium pratense L.) seedlings. African Journal of Biotechnology 10: 8774-8781.

Aşcı ÖÖ, Üney H. (2016) Farklı Tuz Yoğunluklarının Macar Fiğinde (Vicia pannonica Crantz) Çimlenme ve Bitki Gelişimine Etkisi. Akademik Ziraat Dergisi 5(1): 29-34.

Atak M, Mavi K (2016). Bazı serin iklim tahıllarının ilk gelişme döneminde tuz stresine tepkilerinin belirlenmesi. Mustafa Kemal Üni. Zir. Fak. Der. 21(2): 121-129.

Avcı S, ileri O, Kaya MD (2017) Determination of Genotypic Variation among Sorghum Cultivars for Seed Vigor, Salt and Drought Stresses. Journal of Agricultural Sciences 23: 335-343. 
Avcıoğlu R (2014) Çim ekimi dikimi bakımı. Ege Üniversitesi Yayınları Ziraat Fakültesi Yayın no.574, s: 332.

Balkan A, Gençtan T (2013) Ekmeklik buğdayda (Triticum Aestivum L.) osmotik stresin'çimlenme ve erken fide gelişimi üzerine etkisi. Tekirdağ Ziraat Fakültesi Dergisi 10(2) : 44-52.

Berg van den L, Zeng YJ (2006) Response of south african indigenous grass species to drought stress induced by polyethylene glycol (PEG) 6000. South African Journal of Botany 72: 284-286.

Beyazçiçek H, Yılmaz ̧̧ (2020) Bazı yabancı orjinli kinoa (Chenopodium quinoa Willd.) çeşitlerinde tuz stresinin çimlenme ve erken fide gelişimi üzerine etkisi. Mustafa Kemal Üniversitesi Tarım Bilimleri Dergisi 25(2):159-168

Bilgili D, Atak M, Mavi K (2019) Effects of Peg-Induced Drought Stress on Germination and Seedling Performance of Bread Wheat Genotypes. YYÜ. Tar. Bil. Derg. 29(4): 765-771.

Blum A. (1986) Breeding Crop Varieties for Stress Environments, Critical Reviews in Plant Sciences 2: 199-237.

Borawska-Jarmułowicz B, Mastalerczuk G, Gozdowski D, Małuszyńska E, Szydłowska A (2017) The sensitivity of Lolium perenne and Poa pratensis to salinity and drought during the seed germination and under different photoperiod conditions. ZemdirbysteAgriculture 104(1) : 71-78.

Çarpıcı EB, Erdel B (2015) Bazı yonca çeşitlerinde (Medicago sativa L.) kuraklık stresinin çimlenme özellikleri üzerine etkisi. Derim 32(2) : 201-210.

Carrow RL Duncan RR (1998) Salt Affected Turfgrass Sites: Assesment and Managment. Ann Arbor Press, Chelsea, Michigian. P:65.

Castroluna A, Ruiz OM, Quiroga AM, Pedranzani HE (2014) Effects of salinity and drought stress on germination, biomass and growth in three varieties of Medicago sativa L. avences. En Investigacion Agropecuaria 18(1): 39-50.

Dhanda SS, Sethi GS, Behl RK (2004) Indices of drought tolerance in wheat genotypes at early stages of plant growth. Journal of Agronomy and Crop Science 190(1): 6-12.

Ellis RH, Roberts EH (1980) Towards a rational basis for seed testing seed quality. ( P. Hebblethwaitei Editör). In: Seed Production. Butterworths, London, pp.605635.

Ertekin I, Yılmaz Ş, Atak M, Can C (2018) Effects of different salt concentrations on the germination properties of Hungarian vetch (Vicia pannonica
Crantz.) cultivars. Türk Tarım ve Doğa Bilimleri Dergisi 5(2):175-179.

Ertekin I, Yılmaz Ş, Atak M, Can C, Çeliktaş N (2017) Tuz stresinin bazı yaygın fiğ (Vicia sativa L.) çeşitlerinin çimlenmesi üzerine etkileri. Mustafa Kemal Üniversitesi Ziraat Fakültesi Dergisi 22(2):10-18.

Gürbüz A, Kaya M, Türkan AD, Kaya G, Kaya MD, Çiftçi $C Y$ (2009) Bazı nohut (Cicer arietinum L.) çeşitlerinde tane iriliği ve kuraklık stresinin çimlenme özelliklerine etkisi. Akdeniz Ziraat Fakültesi Dergisi 22(1) : 69-74.

Hokmalipour S (2015) Effect of salinity and temperature on seed germination and seed vigor Index of chicory (Chichoriumin tynus L.), cumin (Cuminium cyminium L.) and fennel (Foeniculum vulgare). Indian Journal of Science and Technology 8(35) : 2-9.

Ista, 1996. International rules for seed testing. rules. Seed Science and Technology 24. Supplement.

Kaya MD, Okçu G, Atak M, Çıkılı Y, Kolsarıcı Ö (2006) seed treatments to overcome salt and drought stress during germination in sunflower (Helianthus annuus L). European Journal of Agronomy 24: 291-295.

Khayatnezhad M, Gholamin R (2011) Effects of water and salt stresses on germination and seedling growth in two durum wheat (Triticum durum Desf.) genotypes. Scientific Research and Essays 6(21): 4597-4603.

Khodarahmpour Z (2011) Effect of drought stress Induced by polyethylene glycol (PEG) on germination Indices in corn (Zea mays L.) hybrids. African Journal of Biotechnology 10(79) : 18222-18227

Kuşvuran A, Nazlı RI, Kuşvuran S (2014a) Determination of salinity effects on seed germination in different red fescue (Festuca rubra L.) varieties. Tar. Bil. Ar. Derg. $7(1): 22-27$.

Kuşvuran A, Nazlı RI, Kuşvuran S (2014b) Salinity effects on seed germination in different tall fescue (Festuca arundinaceae Schreb.) varieties. Tar. Bil. Ar. Derg. 7(2): 8-12.

Kuşvuran A, Nazlı RI, Kuşvuran S (2015) The effects of salinity on seed germination in perennial ryegrass (Lolium perenne L.) varieties. Türk Tar. Doğ. Bil. Derg. 2(1): 78-84

Nizam I (2011) Effects of salinity stress on water uptake, germination and early seedling growth of perennial ryegrass. African Journal of Biotechnology 10(51): 10418-10424.

Okçu G, Kaya MD, Atak M (2005) Effects of salt and drought stresses on germination and seedling growth of pea (Pisum sativum L.). Turkish Journal of Agriculture and Forestry 29: 237-242

Oki T, Kanae S (2006) Global hydrological cycles and world water resources. Science 313: 1068-1072. 
Osakabe Y, Osakabe K, Shinozaki K, Tran, LSP (2014) Response of plants to water stress. Frontiers in Plant Science 5(86): 1-8.

Radhouane L (2007) Response of tunisian autochthonous pearl millet (Pennisetum glaucum L. $\mathrm{R}$. Br.) to drought stress induced by polyethylene glycol (PEG) 6000. African Journal of Biotechnology 6(9) : 1102-1105.

Rouhi HR, Aboutalebian MA, Sharif-Zadeh F (2011) Effects of hydro and osmopriming on drought stress tolerance during germination in four grass species. International Journal of Agri. Science 1(2): 701-774.

Topçu GD, Çelen AE, Özkan şS (2016) Farklı tuz konsantrasyonlarının kamışsı yumak (Festuca arundinacea) ve mavi ayrık (Agropyron intermedium) bitkilerinin cimlenme ve erken gelişme donemindeki etkileri uzerine araştırma. Tarla Bitkileri Merkez Araştırma Enstitusu Dergisi 25 (Ozel sayı-2): 219-224.

Turhan A, Kuş̧̧u H, Şeniz V (2011) Effects of different salt concentrations $(\mathrm{NaCl})$ on germination of some spinach cultivars. Uludağ Üniversitesi Ziraat Fakültesi Dergisi 25(1): 65-77.
Wang YR, Yu L, Nan ZB, Liu YL (2004). Vigor tests used to rank seed lot quality and predict field emergence in four forage species. Crop Science 44(2): 535-541.

Yılmaz Ş, Hurmanlı i (2016) Akdeniz bölgesinde bozulmuş çim alanlarında üstten tohumlamanın çim kalitesine etkisi. Tarla Bitkileri Merkez Araştırma Enstitüsü Dergisi 25 (Özel sayı-2): 246-252.

Yılmaz Ş, Hurmanlı I, Yılmaz MB (2018) Çim alanlarında üstten tohumlamanın mevsimsel çim kalitesine etkisi, MKÜ. Ziraat Fakültesi Dergisi 23(1): 97-105.

Zhang Q, Rue, K, Wang S (2012) Salinity effect on seed germination and growth of two warm-season native grass species. Hortscience 47(4): 527-530.

Zhang, Q, Yang L, Rue K (2018) Differences in seedling growth of 23 creeping bentgrass cultivars under polyethylene glycol-induced drought conditions, Horttech 28(3): 327-331. 